\title{
Historias que Abrazan
}

Primero: vivir la desazón. El sismo que tocó nuestro país el 19 de septiembre de 2017 no sólo sepultó personas y acabó con edificios: también hizo emerger la corrupción, la impunidad, la desigualdad y la pobreza. Cosas que estaban en el país desde antes del sismo se hicieron visibles de nuevo. Se desnormalizaron. Nos volvieron a doler. Ver las noticias o transitar por la ciudad era como habitar una herida abierta. El sismo también removió nuestras identidades y seguridades. Nos enfrentó con la caducidad de nuestras respuestas: ¿de qué servía ser profesor universitario o investigador ante una catástrofe de ese tamaño? Pronto nos dimos cuenta de que todos nos sentíamos de manera parecida: también se sentían inútiles los arqueólogos, los arquitectos, las amas de casa, los cocineros... Todas nuestras certezas caducaron. Todas las respuestas aprendidas que sabíamos tuvieron que renovarse. Esa es la experiencia de la crisis, y está vinculada a muchos de los proyectos más nobles que se vivieron en las semanas posteriores.

En ese contexto, el 21 de septiembre nació Historias que Abrazan, colectivo conformado por investigadores universitarios, cuentacuentos y promotores culturales que tenían algún grado de experiencia trabajando en situaciones de crisis y decidieron abrir un espacio de acompañamiento para brigadistas y trabajadores de la cultura que en aquellos momentos se lanzaban a las calles y los albergues con la intención de hacer algo ofreciendo su escucha y su palabra. Muchos de ellos construyeron un espacio de resguardo a través de un cuento, un libro, una canción o un relato. Utilizaron cuentos populares o narraciones para niños para darle relato a la experiencia traumática. Cantaron nanas para tranquilizar a sus hijos o amigos. 
Mientras muchos de nosotros trabajábamos en albergues, centros de acopio o zonas de desastre, nos dimos cuenta de la cantidad de experiencias espontáneas de este tipo que estaban ocurriendo en la ciudad y el país, y decidimos que sería importante ofrecer un espacio para la formación colectiva, responsable y pertinente de las personas involucradas en dichas experiencias. Construimos una página en internet en donde sistematizamos los acervos para trabajar en situaciones de crisis que se había construido en Argentina y Chile, y comenzamos a elaborar materiales propios a partir de nuestra experiencia de lo que funcionaba y no funcionaba. Construimos secuencias didácticas para profesores, cuentos y libros de colorear para los niños... Creamos una sección de cartas abiertas en donde lectores del sitio exponían sus dudas, reflexiones y experiencias, y otros respondían ofreciendo consejo y reflexión o regalando materiales. También extractamos materiales teóricos pertinentes para la situación que estábamos viviendo y ayudamos a crear espacios de reunión entre personas preocupadas en el país y el mundo.

Historias que Abrazan pronto se convirtió en un proyecto de formación ciudadana. Impulsados por Nicté Arzaluz, mediadora con amplia experiencia de trabajo en hospitales, el colectivo diseñó un curso de tres horas para capacitar a brigadistas; en dichos cursos se incluían elementos que ayudaban a hacer trabajo de grupo, contención emocional y planeación en temas de protección civil. Durante dos semanas se impartieron entre uno y dos cursos al día, siempre en zonas distintas de la ciudad. En esas semanas capacitamos a más de 700 brigadistas, además de iniciar un trabajo de acompañamiento más profundo con profesores de la Facultad de Artes y Diseño de la UNAM y con profesoras y estudiantes de la Universidad Autónoma de la Ciudad de México en San Lorenzo Tezonco.

En el camino fuimos construyendo algunos lineamientos de trabajo que hoy nos siguen pareciendo importantes: frente a la soledad compartida de las redes sociales, donde todos gritan sin que nadie se escuche, nos pareció importante fortalecer dinámicas de encuentro entre persona y persona. En el momento de trabajar con niños nos dimos cuenta de la importancia de privilegiar materiales que fortalecen la posición de sujeto del niño, que no sólo lo dibujan como alguien a quien algo terrible le sucede, sino que despiertan preguntas sobre las posibilidades 
de afrontamiento que se ponen en operación en esas situaciones. Al momento de trabajar con brigadistas nos dimos cuenta de la necesidad de plantear el fortalecimiento de la identidad territorial, es decir, de comenzar trabajando con los propios familiares y amigos, en el propio edificio y el propio barrio, activando las redes y organizaciones que ya funcionan allí (como las asambleas vecinales y escuelas), pues todo ello es fundamental para luchar contra la mirada asistencialista que a veces se activa en procesos sociales de crisis. Finalmente, la magnitud de la respuesta a Historias que Abrazan nos hizo darnos cuenta de la necesidad de trabajar desde el fortalecimiento de la autonomía colectiva: no teníamos capacidad para responder a todas las preguntas que nos hacían o de estar en todos los lugares a donde nos pedían ir, pero sí podíamos formar a personas de esos lugares para que ellos, a su vez, replicaran lo que habían aprendido. Lejos de fomentar una cultura de especialistas, Historias que Abrazan se volvió un espacio para experimentar con la construcción ciudadana de conocimiento.

Los materiales construidos siguen disponibles en <http://www.facebook.com/historiasqueabrazan>, y esperamos que les sean útiles a otras personas.

RAFAEL MONDRAGÓN 